\section{Infobugs: agent for contagious transmission of violence, suicide and other social events}

\author{
Henry Xiang
}

The 2020-2021 was an unprecedented time, where the world experienced not one, but two major pandemics: COVID-19 and the incredible spread of violence. Both these pandemics profoundly impacted society as a whole and will have long-lasting consequences and implications for generations to come. As of 14 November 2021, COVID-19 had an astonishing toll with more than 253 million reported infected individuals worldwide and more than 5.0 million reported deaths, ${ }^{1}$ all while the number of infected people and deaths are still rising in some countries. The second pandemic of violence erupted in local communities, regions and nations, and the consequences reach far beyond country borders. The impact of rapidly rising violence was costly and profound, affecting many people around the world.

Dramatic public-health measures such as lockdown, testing and isolating infected people, tracing and quarantining their contacts, social distancing, wearing masks, and COVID-19 vaccines have been proven to slow transmission and decrease mortality. The underlying principle guiding the concept and development of these approaches is the epidemiological triad of infectious disease transmission model. Identifying and sequencing the COVID-19 virus as the biological agent was key in fighting the pandemic and for developing the mRNA vaccines, providing a light of hope at the end of the pandemic tunnel. In contrast, with the violence pandemic, researchers, politicians and the general public are still scratching their heads over vexing questions: how infodemics (a rapid and far-reaching spread of both accurate and inaccurate information) and violence originate, and why they continue to haunt our society. ${ }^{2}$

I hereby wish to suggest an agent for the contagion of the infodemics, violence, suicide and other social events in our society. ${ }^{2-4} \mathrm{I}$ consider this agent to be messages or information that seem to

Correspondence to Dr Henry Xiang, Center for Pediatric Trauma Research \& Center for Injury Research and Policy, Abigail Wexner Research Institute at Nationwide Children's Hospital, Columbus, OH 43220, USA; Henry.Xiang@nationwidechildrens.org mimic biological agents (viruses, bacteria, parasites or other microbes) or chemical contaminants to infect people, and therefore call these 'infobugs'. Infobugs can be defined as physical, electronic or audio messages, images, data information that exist and circulate in a physical, social or virtual environment. The concept of infobugs has novel features which are of considerable social, scientific and intervention policy implications.

A conceptual model, the Haddon Matrix, was proposed by William Haddon $\mathrm{Jr}$ in 1970s and is commonly used to guide ideas for preventing and treating injuries of many types, including those due to violence. ${ }^{56}$ The matrix consists of four columns and three rows that integrate the agent-host-environment concept into targets of change in primary, secondary and tertiary prevention of injuries. Social environment was added in 1998 by Carol Runyan to 'facilitate its application in decision making' ${ }^{7}$ In my opinion, the Haddon Matrix is unsatisfactory in understanding and guiding interventions targeting contagious transmission of violence and suicide for two reasons: first of all, the current Haddon Matrix framework falls short in the mounting evidence showing contagion of violence, suicide and other injuries (eg, motor vehicle fatalities increase just after publicised suicide stories). ${ }^{8}$ Agents proposed in the Matrix are numerous, change by injury types and energy transfer is emphasised as the key for causing injury and designing prevention programmes and policies. Second, the Haddon Matrix was conceptualised and developed before the internet era, and Runyan added the third dimension of the social environment before social media was created. New technology and concepts such as virtual social networking, online dating, violent digital media, cyberbullying, infodemics, infodemiology, infoveillance and so on did not exist.

Sociological and psychological models ${ }^{910}$ and public health approaches ${ }^{11}$ have also suggested the contagion of violence. ${ }^{2}$ Components and structures of these models are multidimensional, and often are too complicated for researchers, policy makers and the general public to grasp. For this reason, I will not comment in detail.

Rather, I wish to put forward the concept of 'infobugs' into the simplest of models of infectious disease transmission: an external agent, a susceptible host, and the environment that brings the host and agent together for understanding contagion of violence, suicide and other positive social events such as kindness and happiness.

I believe infobugs act like biological agents (viruses, bacteria, parasites or other microbes) and may be the root cause of these events in the society. A biological agent refers to an infectious microorganism or pathogen that must be present for a disease to occur. However, the presence of the agent alone is not always sufficient to cause the disease. Likewise, infobugs alone are not always sufficient to cause violence and suicide. A biological agent's pathogenicity (eg, COVID-19 significant high pandemic potential) and dose are key factors for infectious disease transmission. Infobugs pathogenicity (violent message, misinformation) and dose (eg, amount of violent content in media, or amount of misinformation) are determining factors for whether and how many individuals would be infected, and the extent infodemics would circulate in the society. Just as balanced gut microbes are important for an individual's physical and mental health, not all infobugs are harmful and some are crucial for individuals to stay healthy, to be happy, ${ }^{12}$ or to infect other people with kindness. ${ }^{13}$ However, the infection mechanism itself differs; biological agents infect people by attacking a human body system, infobugs infect the mind through reading, social media texting or audio messages and so on.

In terms of hosts, humans can be infected by infobugs but also can 'transmit' infobugs to other human beings. Intrinsic factors can influence an individual's exposure, susceptibility or response to a causative infobug. Opportunities for exposure to infobugs are often influenced heavily by people's online behaviours or their social network contacts. ${ }^{10} \mathrm{~A}$ growing number of researchers and health professionals are using terms such as 'immune system' and 'cyber-immune cells', 'immune' and 'repetitive exposure' to describe individual susceptibility and exposure to infodemics or violence. The connotation of these immunological terms is that infobugs affect certain, but not all individuals in our society.

It is impossible for infobugs to infect individuals without a supportive 
environment. In addition to the physical and social environment described by the Haddon Matrix, the virtual environment including the internet and social media play a crucial role in infobugs spreading, infodemics and contagion of violence, suicide and other social events. The 'vectors' for spreading infobugs include newspapers, webpages, social media platforms, smartphones, and other electronic devices.

I posit that infobugs could be characterised using a schema or be encoded using the computer binary codes. Sequencing and analysing an infobug's unique arrangement of binary codes would be much like DNA sequencing and genome analysis. This could be an interesting and a potentially rewarding field. Such efforts could be useful for infodemiology, infoveilance, prevention and control of infodemics, monitoring and containing contagion of violence and suicide in our society and promoting happiness, kindness, and well-being.

In 1998, Enrico Coiera stated that 'we need a model of the public's information behaviour to guide our actions as an epidemic of misinformation on internet was beginning'. ${ }^{14}$ Twenty years later, the World Health Organization sounds a loud alarm, stating 'never before has there been a more urgent need for a coordinated, evidence-based approach to mitigating the harm caused by an infodemic and the spread of health information'. ${ }^{4}$ The proposed infobugs concept using the traditional epidemiological triad of infectious diseases could easily be relayed to the general public and facilitates social discussion, research, development of interventions and policies.

Acknowledgements I thank Dr Lorann Stallones, Dr Tanya Menson, Jonathan Lun and Joe Xiang for reading the manuscript and sharing useful comments.

Contributors HX conceptualised and drafted the manuscript. He approved the final version for publication.

Funding The author has not declared a specific grant for this research from any funding agency in the public, commercial or not-for-profit sectors.

Competing interests None declared.

Patient and public involvement Patients and/or the public were not involved in the design, or conduct, or reporting, or dissemination plans of this research.

Patient consent for publication Not applicable.

Ethics approval This study does not involve human participants.

Provenance and peer review Commissioned; internally peer reviewed.

(C) Author(s) (or their employer(s)) 2022. No commercial re-use. See rights and permissions. Published by BMJ.

\section{D) Check for updates}

To cite Xiang H. Inj Prev 2022;28:1-2.

Published Online First 15 December 2021

Inj Prev 2022;28:1-2.

doi:10.1136/injuryprev-2021-044485

\section{ORCID iD}

Henry Xiang http://orcid.org/0000-0001-8112-319X

\section{REFERENCES}

1 Johns Hopkins University. Johns Hopkins coronavirus resource center, 2021. Available: https://coronavirus. jhu.edu [Accessed 14 Nov 2021].
2 National Research Council. Contagion of violence: workshop summary. Washington, DC: The National Academies Press, 2013.

3 Rothkopf DJ. When the buzz bites back. The Washington post, 2003. Available: https://www. washingtonpost.com/archive/opinions/2003/05/11/ when-the-buzz-bites-back/bc8cd84f-cab6-4648-bf580277261af6cd/ [Accessed 7 Jul 2021].

4 World Health Organization. WHO public health research agenda for managing Infodemics. Geneva, Switzerland: World Health Organization, 2021.

5 Baker SP, Haddon W. Reducing injuries and their results: the scientific approach. Milbank Mem Fund Q Health Soc 1974;52:377.

6 Haddon W. On the escape of tigers: an ecologic note. Am J Public Health Nations Health 1970;60:2229-34.

7 Runyan CW. Using the Haddon matrix: introducing the third dimension. Inj Prev 2015;21:126-30.

8 Phillips DP. Motor vehicle fatalities increase just after publicized suicide stories. Science 1977;196:1464-5.

9 Krahé B, Möller I, Huesmann LR, et al. Desensitization to media violence: links with habitual media violence exposure, aggressive cognitions, and aggressive behavior. J Pers Soc Psychol 2011;100:630-46.

10 Christakis NA, Fowler JH. Connected: the surprising power of our social networks and how they shape our lives. New York, NY: Little, Brown, 2009.

11 Browne KD, Hamilton-Giachritsis C. The influence of violent media on children and adolescents:a publichealth approach. Lancet 2005;365:702-10.

12 Fowler JH, Christakis NA. Dynamic spread of Happiness in a large social network: longitudinal analysis over 20 years in the Framingham heart study. BMJ 2008;337:a2338.

13 Zaki J. Kindness contagion: witnessing kindness inspires kindness, causing it to spread like a virus. scientific American, 2016. Available: https://www. scientificamerican.com/article/kindness-contagion/ [Accessed 14 Nov 2021].

14 Coiera E. Information epidemics, economics, and immunity on the Internet. we still know so little about the effect of information on public health. BMJ 1998:317:1469-70. 